\title{
Proceeding
}

Supplementary Issue: Summer Conferences of Sports Science. Costa Blanca Sports Science Events, 20-21 September 2019. Alicante, Spain.

\section{Building and codification of the emotional equilibrium measure and its relationship with some of the offensive skills of basketball players for the season (2016 - 2017)}

\author{
ALI M. HAMIDI $\triangle$, KARAR A. MOTAIR, RASOL R. MASHAAV \\ Faculty of Physical Education and Mathematical Sciences, Maysan University, Iraq
}

\begin{abstract}
The study aimed to: to build the emotional equilibrium measure for basketball youth players to identify the relationship between the emotional equilibrium measure and some of the offensive skills for the basketball youth players in Maysan province. The researchers proposed that there is a statistical relationship between the emotional equilibrium measure and some of the offensive skills for the basketball youth players in Maysan province. The researchers concluded that the effectiveness of the emotional equilibrium measure for the Theoretical and practical aspect of the players, the results of the emotional equilibrium measure for the Chest Pass was moral from the results that the players got, the researchers reached the following recommendation The need to take care of the general psychological preparation of players through the training process with special attention to the development of the skill levels of the basketball players in the Psychological traits especially the emotional equilibrium trait, because the distinguished players with high level emotional equilibrium are more capable to take advantage of their physical ability, skills and following plans which contribute to winning superior then their peers. The exploratory experiment was conducted on 7/7/2016 and up to $72 / 7 / 2016$ to demonstrate the validity of the scale to a sample of 15 players representing the Ali alGharbi Sports Basketball Club in Maysan Governorate. The researchers used the internal consistency coefficient with sincerity of construction and it measures the relationship between the scale total degree and the grades of each paragraph, because the coefficient of differentiation does not determine. Keywords: Emotional equilibrium; Offensive skills; Basketball.
\end{abstract}

Cite this article as:

Hamidi, A.M., Motair, K.A., \& Mashaav, R.R. (2019). Building and codification of the emotional equilibrium measure and its relationship with some of the offensive skills of basketball players for the season (2016 - 2017). Journal of Human Sport and Exercise, 14(5proc), S1853-S1862. doi:https://doi.org/10.14198/ihse.2019.14.Proc5.04

Corresponding author. Faculty of Physical Education and Mathematical Sciences, Maysan University, Iraq.

E-mail: Sport_sport190@yahoo.com

Supplementary Issue: Summer Conferences of Sports Science. Costa Blanca Sports Science Events, 20-21 September 2019. Alicante, Spain.

JOURNAL OF HUMAN SPORT \& EXERCISE ISSN 1988-5202

(c) Faculty of Education. University of Alicante

doi:10.14198/jhse.2019.14.Proc5.04 


\section{INTRODUCTION}

The modern era is characterized by scientific progress in many fields, especially the sports field through the activities and events in it. Currently Psychology is considered one of the most important things that the science must take care of and focus on because of its influence on the human being in terms of studying his behaviours and personality, also it studies the human beings in terms of their coexistent and relationship with their environment and the effects it implements on them whether it was positive or negative and to try to amend it or finding proper solutions for it. The Psychological factor has an important role on the progress and development of the player level and performance stability by preparing him psychologically for the competitions, the emotional equilibrium is considered one of the effecting factors in the player's performance level and it has a big role in the enhancement and development of the performance. The lack of Psychological preparation reduces the player's ability and performance and effects the team as a whole, and that's why we should take care of the Psychological aspects through identifying the problem in the team and diagnosing the team Psychological aspects. the emotional equilibrium attracted a lot of interest by the researchers in the psychology field in all its branches. Basketball game is considered one of the sport activities in which the player is making a very big physical effort over the four periods of the match which leads to a great psychological pressure on the players, and from that the Importance of research Hence the importance of research to think about Building and codification of the emotional equilibrium measure for the participated clubs players in the NBA and the relationship between the measure and some of the offensive skills and this will leads to identify some psychological aspects Which, if taken care of, will help to reach the advanced level of players ' performance during sports competitions.

\section{The research problem}

There is no doubt that emotions have a major impact on the training process which is associated with the player personality as the axis around which the training and educational process revolves through which it seeks to build his personality according to Scientific and health bases. The training goal is not to just train the physical aspect of the player but to care for his personality as a whole in its mental and psychological aspects to make him a true athlete who is confident of his abilities and capabilities and aware of what he has and what he has to do and what must he do for an influential and meaningful act, because players are exposed to a lot of psychological factors and stress in all matches, basketball is considered one of team based activities which demands great physical qualities and skills, and this requires the player to be on top of his game and become an emotionally balanced athlete. And according to the researcher's humble experience as a former player and a referee in basketball field and a teacher for this subject he sees that the psychological aspect did not have the required attention from the trainers because the modest level of the participated teams plus there was no measure for the emotional equilibrium suits the youth players in Maysan province and how this scale is related to the offensive skills in basketball.

\section{Research objectives}

- Building and codification the emotional equilibrium measure for the basketball youth players in Maysan province.

- Identifying the relationship between the emotional equilibrium and some of the offensive skills of basketball players in Maysan province.

\section{The research imposed}

There is a statistical relationship between the emotional equilibrium and some of the offensive skills of basketball players in Maysan province. 


\section{The research fields}

Human field: Maysan province youth players for the sport season (2016 - 2017).

Temporal sphere: The period from 01/07/2016 to 02/09/2016.

Spatial sphere the club's stadiums included in the research.

\section{MATERIALS AND METHODOLOGY}

\section{Research Methodology}

The researcher used a descriptive approach in the interconnectivity style for its suitability to solve the problem, it is one of the basic approaches in descriptive research "The descriptive approach seeks to collect data from community members to determine its current state with a one variable or certain variables."

\section{Participants}

The research included the players of Maysan Governorate for basketball clubs for Youth at the age of (1618) years participating in the province League for the sports season $(2016-2017)$ and by a sample size of $120^{*} 2$ players representing 8 local clubs chosen by an intentional manner. The research procedures were performed on them as a sample of construction, codification and application, 15 players were disqualified for their participation in the exploratory experiment. the emotional equilibrium measure draft form was distributed on them and this sample represents $87.5 \%$ of the whole research community.

\section{Measures}

The researchers used a number of research tools to access the privet information of the study which is the questionnaire form, personal interview 3, which included the building and codification of the emotional equilibrium measure of the basketball players, as well as the use of some tests for some of basketball the attack s offensive skills, The study procedure is described below.

Cronbach 1970 emphasizes that researchers should start by identifying the concepts that is relied on in the measure building before they start with the research building procedure. ${ }^{2}$

The preparation of an emotional equilibrium measure requires several procedures that begin with the process of drafting paragraphs to suit the research community, as well as instructions on how to answer them, how to correct them, and these procedures are: the researchers have familiarized themselves with sources, references, studies, measurements and questionnaires. in general psychology and Sport Psychology Which relates to the literature of the emotional equilibrium. Hence the scale designed by (Abdul Aoun Jafar alMassoudi 2002) \$ which consists of 87 paragraphs, to measure the emotional equilibrium, the researchers in the sports field used it in accordance with the Iraqi environment.

\section{Determination of the method for drafting and answering paragraphs}

The preparation of the psychiatric measurements is the most important step in its construction, as the accuracy of the scale depends on the paragraph accuracy and its representation trait which needs to be measured. Thus, the researcher should be fully aware of the conditions for the preparation of paragraphs and their specifications, as the standard characteristics (psychometric) of the scale depend to a large extent on the standard characteristics (psychometric) of the paragraphs. ${ }^{3}$ In the presentation of the measure and

\footnotetext{
${ }^{1}$ Allawi, M.H.\& Rateb,O.K.(1999).scientific Research in Physical Education and Sports Psychology. Cairo, Egypt: Dar Al-Fikr AlArabi.

2 Cronbach, L. J. (1972). Essential of Psychological Testing. New York, United states: Happer and Baw Publishers.

${ }^{3}$ Abdul Khaleq, A.M. (1989). Basic dimensions of Personality. Alexandria, Egypt: Dar al-Maarifah al-Jami'a.
} 
the drafting of the paragraphs, the researchers considered the opinions of the Experts\$, and three areas were selected instead of four, the first area was (the authentic expression of emotions) to become (genuine interaction with colleagues), and the second area (inherent presence with others) to become the future outlook for the athlete), while the third area, (courage in facing the future) to become (force of decision making), and based on Likert method five alternatives were used to answer the paragraphs which are, (it applies to me exactly - applies to me often - applies to medium degree - not applicable to me often - not applicable to me ever), the scale paragraphs took into account the following:

1. The paragraph should contain a single phrase.

2. Not to use phrases that are likely to be answered or not answered by all participant, so that researchers do not have a chance to do so.

3. The words should be phrased in the speaker's form.

4. The paragraphs should be free of any hint of the correct answer.

\section{Drafting of the scale paragraphs}

One of the conditions for building psychological standards is that their paragraphs are understandable and the instructions for answering them are clear to those for the participant and the true purpose of the measure (i.e. not to write the metric name) must be concealed to obtain truthful data\$.by relying on the foundations contained in research and scientific studies on Methods of constructing and legalizing of psychological scales, 63 paragraphs were drafted to measure the emotional equilibrium after excluding 24 paragraphs for the scale designed by (Abdul Aoun Jafar al-Massoudi 2002) the proposed paragraphs were presented to the experts, and they mentioned the validity of all paragraphs to measure the purpose for which they were designed for.

\section{Procedures}

The exploratory experiment was conducted on 7/7/2016 and up to 72/7/2016 to demonstrate the validity of the scale to a sample of 15 players representing the Ali al-Gharbi Sports Basketball Club in Maysan Governorate, the purpose of which was to conduct the experiment as follows:

1. Prepare the first picture of the scale paragraphs Before being analysed by a specialist.

2. $\quad$ To identify the appropriateness of the paragraphs prepared for this purpose.

3. The clarity and degree of responsiveness of the paragraphs in the search sample.

4. Calculating the response time and the time it takes for the player to answer the paragraphs of the two scales the answering time ranges from (25 to 30$)$ minutes.

5. Ensure clarity of the scale's instructions and responsiveness of the participants and their understanding of the tests.

6. Avoid unclear language and alter it with appropriate terms.

\section{Analysis}

The current measure was worded in two directions (negative and positive) and five alternatives were given weights ranging from (5.1) According to the response sequence for the positive paragraphs and weights ranging from (1-5) were given for negative paragraphs. 


\section{RESULTS}

Table 1. Shows the calculated $(\mathrm{t})$ value the theoretical and arithmetic mean of the emotional equilibrium measure.

\begin{tabular}{llllll}
\hline $\begin{array}{l}\text { Significance } \\
\text { level }\end{array}$ & $\begin{array}{l}\mathrm{t} \text { calculated } \\
\text { value }\end{array}$ & $\begin{array}{l}\text { Standard } \\
\text { deviation }\end{array}$ & $\begin{array}{l}\text { Arithmetic } \\
\text { mean }\end{array}$ & $\begin{array}{l}\text { Theoretical } \\
\text { mean }\end{array}$ & $\begin{array}{l}\text { Number of the scale } \\
\text { paragraphs }\end{array}$ \\
\hline 0.00 & 21.10 & 12.40 & 214.54 & 189 & 63 \\
\hline
\end{tabular}

Table 5 shows that the number of paragraphs of the scale (emotional equilibrium) are (63) Paragraphs, and in the Theoretical mean (189), while the search sample arithmetic means of (214.54), and with a standard deviation (12.40). As ( $t$ ) calculated between the theoretical and calculated mean for the research sample (21.10) and the significance level (0.00), indicating Its reliability at an indication level $(0.05)$ it was found that the arithmetic mean is greater than the theoretical mean. Which means that there are moral differences in favour of arithmetic mean.

Table 2. Shows the results of the Arithmetic means and Standard Deviations and the value of calculated ( $r$ ) and tabular ( $r$ ) and the significance level for the emotional equilibrium and some basketball offensive skills.

\begin{tabular}{llllllll}
\hline Significance & $\begin{array}{l}\text { Significance } \\
\text { level }\end{array}$ & $\begin{array}{l}\text { Tabular } \\
(r) \\
\text { value }\end{array}$ & $\begin{array}{l}\text { Calculated } \\
(r) \text { value }\end{array}$ & $\begin{array}{l}\text { standard } \\
\text { deviation }\end{array}$ & $\begin{array}{l}\text { Arithmetic } \\
\text { mean }\end{array}$ & $\begin{array}{l}\text { Measurement } \\
\text { Unit }\end{array}$ & Variables \\
\hline Moral & 0.04 & 0.174 & 0.653 & 0.72 & 8.47 & Second & $\begin{array}{l}\text { Chest } \\
\text { equilibrium }\end{array}$ \\
Moral & 0.02 & 0.174 & 0.844 & 0.85 & 10.19 & Second & Pass \\
Moral & 0.02 & 0.174 & 0.237 & 1.56 & 12.07 & Grade & Free \\
Moral & 0.00 & 0.174 & 0.628 & 1.81 & 10.94 & Grade & throws \\
Jump shot \\
\hline
\end{tabular}

Presentation, analysis and discussion of the results of the emotional equilibrium measure and its relationship with some of the offensive basketball skills:

Note that the value of $(\mathrm{t})$ tabular $=0.25$, With a Significance mean $=0.005$, with a degree of freedom equalling $(n-2)$.

Its noted that from the above results shown in the table above, the calculated correlation values of the emotional equilibrium measure and the offensive skills were greater than the tabular value, so the values between each skill and the emotional equilibrium measure test are as follows: With the chest pass test its correlation value reached $(0.653$ which Is greater than the tabular value $(0.174)$, which indicates a correlation between emotional equilibrium and chest pass. While the drippling tests its correlation value reached $(0.844)$ which Is greater than the tabular value (0.174), which indicates a correlation between emotional equilibrium and drippling. Whereas scoring speed test by jumping its correlation value reached $(0.628)$ which Is greater than the tabular value (0.174), which indicates a correlation between emotional equilibrium and the free throw skill. The researchers attribute these findings showing in tables (5) and (6) that whenever players are subjected to emotional distress during training, this means that there is a psychological pressure on the players and therefore their performance is different as a result of the influence of psychological pressure and 
its threat level differ between a player and another according to the type of pressure, its size, its strength, its extent, the psychological build-up of the athlete, his ability, the efficiency of his muscular and nervous organs, the integrity of his personality, his will to resist and not to bow to these pressures, how he feels and how he control the events. ${ }^{4}$ the results showed that there was a correlation between Emotional and offensive basketball skills researchers attribute the reason for this correlation that the higher the emotional poise in practical training the higher the level of skill performance due to the physical and mental changes associated with emotional weights which involved the positive side which pushed the players Towards a more effective performance and this is confirmed by Kazem Waly " When The player exercise continuously and according to the training curriculum assigned to him in the training unit he feels the emotional equilibrium on the completion of the Exercise "5 researchers sees that the correlation between the emotional equilibrium and the offensive skills reflects the positive relationship and its impact on the players performance skills, through the results obtained by the players from the responses to the paragraphs of the emotional equilibrium measure and this is consistent with many researchers "in some cases the emotional equilibrium is useful for the player, especially when he do the exercise and prepares well for it and deplete all his energies to perform it"6.

The researchers also emphasize the emotional equilibrium persistence and progress in movement or skill is achieved only through training, repetition and avoidance of errors, and this is done through practical training and under the supervision of the trainer and this is one of the main lines in the correlation between emotional equilibrium and offensive skills in Basketball, players who combine emotional and skill training are more likely than others to achieve good results when compared to other players who lack psychological skills.

\section{DISCUSSION}

A good scale specification is to conduct a statistical analysis for its paragraphs to differentiate between individuals who have obtained high scores and who have obtained low scores in the same scale, which means the extraction of the discriminatory force of paragraphs. ${ }^{7}$ That the scale characteristics of depend to a large extent on the characteristics of the psychometric for its paragraphs The more the characteristics of the paragraphs are high in their grades or their differential power, they give an indication on the scale accuracy and its ability to measure what it is designed to measure, and the statistical analysis of the emotional equilibrium measure was conducted in two ways:

\section{The internal consistency factors}

The researchers used the internal consistency coefficient with sincerity of construction and it measures the relationship between the scale total degree and the grades of each paragraph, because the coefficient of differentiation does not determine the homogeneity of each paragraph with the scale total measurement "the coefficient of distinction between the upper and lower groups measures the distinction of each paragraph and does not specify the Paragraphs homogeneity in Its measurement of the behavioural Phenomenon"8,

\footnotetext{
${ }^{4}$ Ali, KH.A. \& El-Hilali, E. (2014). The Sports Meeting. Cairo, Egypt: Dar Elfekr Elaraby.

${ }^{5}$ Agha, K.W. (2015). Emotional Equilibrium and Collection, A Comparative Study of the Relationship of Educational Achievement in Males and Females in the United Arab Emirates. Babel, Iraq: Journal of Humanities.

${ }^{6}$ El-Sabbagh, W.M. (2009). Building a measure of the exam anxiety for the preparatory stage students. Mosul, Iraq: Faculty of Education, Mosul University.

7 Samoum, A. \& others (2015). Measurement, Testing and Evaluation in the Mathematical Field. Baghdad, Iraq: Iraq National Library and Archive.

${ }^{8}$ Al-Samarrai, B.N.\&Al-Baldawi, T.H. (1978). Students' Attitudes toward the Teaching Profession. Iraq: Journal of Educational Research.
} 
therefore uses the internal consistency coefficient, as it " gives us evidence of the homogeneity of the Paragraphs"9. "the internal consistency coefficient is the coefficient of correlation between the grades of each paragraph and the total degree of the scale" ${ }^{10}$ and to find the internal consistency coefficient Pearson correlation factor was used between the degree of each paragraph and the scale total degree and all the members of the sample (105) players and it turns out that all the scale paragraphs are a statistical function when it is compared with the value of ( tabular $r$ ) which equals $(0.174)$ of the index $(0.05)$ below the level of significance $(0.5)$ and the freedom degree $(n-2)=105-2=103$, since it turned out that all of the emotional equilibrium measure paragraphs were moral because its calculated value is greater than the tabular value, as the correlation values of the resolution paragraphs is ranged between $(0.227-0.743)$, and table (3) shows that.

Table 3. Pearson's simple correlation coefficients to examine the validity of the emotional equilibrium paragraphs for the search sample using the internal consistency method between each paragraph's responses and the overall degree of scale.

\begin{tabular}{cccccccc}
\hline $\begin{array}{c}\text { Correlation } \\
\text { coefficient }\end{array}$ & $\begin{array}{c}\text { Paragraph } \\
\text { number }\end{array}$ & $\begin{array}{c}\text { Correlation } \\
\text { coefficient }\end{array}$ & $\begin{array}{c}\text { Paragraph } \\
\text { number }\end{array}$ & $\begin{array}{c}\text { Correlation } \\
\text { coefficient }\end{array}$ & $\begin{array}{c}\text { Paragraph } \\
\text { number }\end{array}$ & $\begin{array}{c}\text { Correlation } \\
\text { coefficient }\end{array}$ & $\begin{array}{c}\text { Paragraph } \\
\text { number }\end{array}$ \\
\hline 0.418 & 52 & 0.442 & 35 & 0.321 & 18 & 0.424 & 1 \\
0.529 & 53 & 0.572 & 36 & 0.438 & 19 & 0.365 & 2 \\
0.472 & 54 & 0.474 & 37 & 0.546 & 20 & 0.328 & 3 \\
0.316 & 55 & 0.587 & 38 & 0.567 & 21 & 0.542 & 4 \\
0.328 & 56 & 0.631 & 39 & 0.328 & 22 & 0.589 & 5 \\
0.429 & 57 & 0.352 & 40 & 0.743 & 23 & 0.325 & 6 \\
0.549 & 58 & 0.532 & 41 & 0.439 & 24 & 0.279 & 7 \\
0.335 & 59 & 0.234 & 42 & 0.571 & 25 & 0.227 & 8 \\
0.438 & 60 & 0.258 & 43 & 0.319 & 26 & 0.407 & 9 \\
0.342 & 61 & 0.341 & 44 & 0.371 & 27 & 0.442 & 10 \\
0.347 & 62 & 0.478 & 45 & 0.490 & 28 & 0.590 & 11 \\
0.482 & 63 & 0.539 & 46 & 0.427 & 29 & 0.411 & 12 \\
& & 0.358 & 47 & 0.352 & 30 & 0.347 & 13 \\
& & 0.529 & 48 & 0.631 & 31 & 0.622 & 14 \\
& & 0.523 & 49 & 0.534 & 32 & 0.345 & 15 \\
& & 0.341 & 50 & 0.561 & 33 & 0.467 & 16 \\
\hline
\end{tabular}

\section{The style of the two extremist groups}

The objective of the paragraphs analysis is to ensure that they are enough to achieve the individual differences principle on which the measure is based, so that the force is calculated for the purpose of retaining the distinctive paragraphs and deleting the non-characteristic paragraphs. the players scores are ranked in a descending way based on the method of the two extremist groups, as $27 \%$ were selected from the upper grades and the lower grades to represent the two extremist groups, Stanley and Hopkins asserts, "this ratio makes the two groups ideal by size and differentiation ${ }^{11}$, with grades divided into a higher part and a lower part of the grades one of them represents the individuals who obtained the highest scores. The second represents the individuals who obtained the lowest scores, and each group represents a ratio of (27\%) from

\footnotetext{
${ }^{9}$ Bahi,M.H.(1999).Scientific Transactions between Theory and Practice.Cairo,Egypt:The Book Center for Publishing.

10 Kadhim, A.M. (1994). Building a Codified Scale for Personal Characteristics of the Preparatory Stage in Iraq. Baghdad, Iraq: Faculty of Education Ibn al-Rashed University of Baghdad.

11 Stanly, C. J. \& Hopkins, K. D. (1972). Education and Psychological., New York, United state: Englewood Cliffs, N.J.: Prentice Hall.
} 
the sample Members of and thus the researchers have two sets of high and low groups each one of them have (28) players. To calculate the paragraph distinction force, the law of ( $t$ ) calculated, was used and when its compared with the value of $(t)$ tabular which equals (2.00) below the level of significance $(0.5)$ and the freedom degree $(n+N-2)=28+28-2=54$. All the emotional equilibrium measure paragraphs were distinctive because its calculated value is greater than its tabular value after the use of the statistical processes to extract the discriminatory force of the emotional equilibrium resolution paragraphs the following results emerged:

1. The discriminatory force of the resolution paragraphs ranged from (4.59-17.91).

2. There is no paragraph excluded from the resolution and table (2) shows the discriminatory force for each of the resolution paragraphs.

Table 4. Shows the coefficient of discrimination calculated value for the emotional equilibrium resolution paragraphs for extremist groups.

\begin{tabular}{cccccccc}
\hline $\begin{array}{c}t \text { calculated } \\
\text { value }\end{array}$ & $\begin{array}{c}\text { Paragraph } \\
\text { number }\end{array}$ & $\begin{array}{c}\mathrm{t} \text { calculated } \\
\text { value }\end{array}$ & $\begin{array}{c}\text { Paragraph } \\
\text { number }\end{array}$ & $\begin{array}{c}\mathrm{t} \text { calculated } \\
\text { value }\end{array}$ & $\begin{array}{c}\text { Paragraph } \\
\text { number }\end{array}$ & $\begin{array}{c}\mathrm{t} \\
\text { calculated } \\
\text { value }\end{array}$ & $\begin{array}{c}\text { Paragraph } \\
\text { number }\end{array}$ \\
\hline 4.73 & 52 & 7.334 & 35 & 6.31 & 18 & 23.34 & 1 \\
9.28 & 53 & 9.52 & 36 & 9.48 & 19 & 17.52 & 2 \\
11.55 & 54 & 12.59 & 37 & 13.45 & 20 & 16.28 & 3 \\
16.28 & 55 & 14.29 & 38 & 7.59 & 21 & 15.79 & 4 \\
8.29 & 56 & 8.44 & 39 & 15.38 & 22 & 11.27 & 5 \\
13.21 & 57 & 6.57 & 40 & 17.33 & 23 & 8.33 & 6 \\
17.91 & 58 & 11.78 & 41 & 13.49 & 24 & 6.57 & 7 \\
10.22 & 59 & 5.43 & 42 & 5.17 & 25 & 7.72 & 8 \\
7.30 & 60 & 8.59 & 43 & 7.32 & 26 & 5.47 & 9 \\
6.43 & 61 & 12.45 & 44 & 10.29 & 27 & 12.32 & 10 \\
5.77 & 62 & 4.59 & 45 & 8.47 & 28 & 11.59 & 11 \\
14.52 & 63 & 7.87 & 46 & 11.57 & 29 & 6.51 & 12 \\
& & 9.59 & 47 & 6.33 & 30 & 8.45 & 13 \\
& & 6.77 & 48 & 9.49 & 31 & 9.13 & 14 \\
& & 8.45 & 49 & 12.38 & 32 & 15.59 & 15 \\
& & 12.42 & 50 & 15.33 & 33 & 12.56 & 16 \\
& & 11.77 & 51 & 6.39 & 34 & 7.23 & 17 \\
\hline
\end{tabular}

\section{The scale stability}

stability is a necessary indicator and researchers relied on a half-retail method because it requires a onetime test, and the data obtained by researchers related to the degree answers of (15) player. This method relies on dividing the test into two parts, the first part includes Paragraphs with odd numbers, and the second part contains paragraphs bearing even numbers. As the Pearson correlation coefficient was calculated between the grades it indicated above (0.853), but this method represents the stability coefficient of half the test so it must be corrected in order to measure the test as a whole. the researchers used the SpermanBrown equation in order to correct the coefficient and thus the scale stability $(0.920)$ which is considered a good and reliable standard.

Final description of the emotional equilibrium measure

After the researchers have completed the scientific transactions necessary for the emotional equilibrium measure through the preceding procedures, the measure became consisted of (63) paragraphs in its final 
image appendix (1) and to answer it, is by selecting five alternatives (apply too much counts as five degrees), (and four degrees to the answer) apply Too much), (three degrees to the answer apply moderately), (two degrees for the answer apply slightly), (and finally one degree for the answer it is not applicable to me), the scale total degree ranged from $(63-315)$ and the degree of neutrality (189).

\section{Basketball Skills Tests}

The researchers used some of the offensive skills such as (chest pass, Dribbling, free throws, jump shot) and relying on scientific sources and references, the researchers selected a set of codified tests as follows:

1- $\quad$ Chest pass ${ }^{12}$

2- $\quad$ Dribbling 13

3- $\quad$ Free throws ${ }^{14}$

4- $\quad$ Scoring Speed Test 15

\section{Statistical means}

1- $\quad$ Arithmetic mean

2- $\quad$ Standard deviation

3- Significance factor

4- $\quad(t)$ test

5- $\quad$ Percentage

\section{CONCLUSIONS}

1- The efficacy of the emotional equilibrium measure in the theoretical and practical aspect of the players.

2- $\quad$ The relationship that emerged is a positive relationship between the emotional equilibrium and some of the offensive skills (Chest pass, Dribbling, scoring speed, Free throws) in basketball.

\section{RECOMMENDATIONS}

1- $\quad$ The need to pay attention to the general psychological preparation of the players through the training process, with special attention to the development of the level of the basketball players in the psychological characteristics and especially the characteristic of emotional equilibrium, since the players who are distinguished with high levels of emotional equilibrium more to benefit from others in their physical and skill abilities and implement the plans to contribute to win.

2- $\quad$ Take care to conduct psychological tests on the players through the training process so as to contribute to the early detection of the distinctive character dimensions of the basketball players.

3- Conduct similar studies to the emotional equilibrium and its relationship with some other variables in order to achieve athletic achievement.

4- $\quad$ Conduct similar studies to the emotional equilibrium and its relationship with some individual and team events.

5- $\quad$ Conducting similar studies to the emotional equilibrium and for different age groups.

\footnotetext{
${ }^{12} \mathrm{Abd}$ al-Deem, M.M. \&Hassanein, M.H. (1984). Measurement in Basketball. Cairo, Egypt: Dar Al-Fikr Al-Arabi.

${ }^{13}$ Allawi, M.H.\& Radwan, M.N. (1987). The tests of skill and psychological in the field of sports. Cairo, Egypt: Dar al-Fikr al-Arabi.

${ }_{14}$ Majid, R.K. (1998). Encyclopedia of Tests in Physical Education and Sports. Basra, Iraq: Iraq National Library and Archive.

${ }^{15} \mathrm{Abd}$ al-Deem, M.M. \&Hassanein, M.H. (1984). Measurement in Basketball. Cairo, Egypt: Dar Al-Fikr Al-Arabi.
} 


\section{REFERENCES}

Abd al-Deem, M.M. \&Hassanein, M.H. (1984). Measurement in Basketball. Cairo, Egypt: Dar Al-Fikr AlArabi.

Abdul Khaleq, A.M. (1989). Basic dimensions of Personality. Alexandria, Egypt: Dar al-Maarifah alJami'a.

Agha, K.W. (2015). Emotional Equilibrium and Collection, A Comparative Study of the Relationship of Educational Achievement in Males and Females in the United Arab Emirates. Babel, Iraq: Journal of Humanities.

Ali, KH.A. \& El-Hilali, E. (2014). The Sports Meeting. Cairo, Egypt: Dar Elfekr Elaraby.

Allawi, M.H.\& Radwan, M.N. (1987). The tests of skill and psychological in the field of sports. Cairo, Egypt: Dar al-Fikr al-Arabi.

Allawi, M.H.\& Rateb,O.K.(1999).scientific Research in Physical Education and Sports Psychology. Cairo, Egypt: Dar Al-Fikr Al-Arabi.

Al-Masoudi, A. A. (2002). Emotional Equilibrium among University Students. Baghdad, Iraq: University of Baghdad, Faculty of Education, lbn al-Haytham. https://doi.org/10.31642/jokmc/2018/060103

Al-Samarrai, B.N.\&Al-Baldawi, T.H. (1978). Students' Attitudes toward the Teaching Profession. Iraq: Journal of Educational Research.

Anastasia, A. (2014). Psychological Testing. New York, United states: Macmillan Publishing Co, Inc.

Al-Zubaidi, A.A.\& Others. Psychological stress and its relation to creative thinking among basketball players. Tikrit, Iraq: Sport culture journal.

Bahi,M.H.(1999).Scientific Transactions between Theory and Practice. Cairo, Egypt: The Book Center for Publishing.

Cronbach, L. J. (1972). Essential of Psychological Testing. New York, United states: Happer and Baw Publishers.

El-Sabbagh, W.M. (2009). Building a measure of the exam anxiety for the preparatory stage students. Mosul, Iraq: Faculty of Education, Mosul University.

Kadhim, A.M. (1994). Building a Codified Scale for Personal Characteristics of the Preparatory Stage in Iraq. Baghdad, Iraq: Faculty of Education Ibn al-Rashed University of Baghdad. https://doi.org/10.22401/inus.15.2.05

Majid, R.K. (1998). Encyclopedia of Tests in Physical Education and Sports. Basra, Iraq: Iraq National Library and Archive.

Robert M. Thorndike \& Tracy M. Thorndike-Christ (2015). Measurement and Evaluation. New Jersey, United states: Prentice Hall.

Samoum, A. \& others (2015). Measurement, Testing and Evaluation in the Mathematical Field. Baghdad, Iraq: Iraq National Library and Archive.

Stanly, C. J. \& Hopkins, K. D. (1972). Education and Psychological., New York, United state: Englewood Cliffs, N.J.: Prentice Hall.

\section{(ब) $\oplus \Theta \Theta$}

This work is licensed under a Attribution-NonCommercial-NoDerivatives 4.0 International (CC BY-NC-ND 4.0). 